\title{
Uncertain Words, Uncertain Texts. Perception and Effects of Uncertainty in Biomedical Communication
}

\author{
Isabella Poggi, Francesca D'Errico, Laura Vincze \\ Università Roma Tre, Dipartimento di Filosofia, Comunicazione e Spettacolo \\ Via Ostiense 234 - 00146 - Roma - Italy \\ isabella.poggi@uniroma3.it, francesca.derrico@uniroma3.it
}

\begin{abstract}
Literature on epistemic stance has thoroughly investigated certainty and uncertainty markers, but their effects on the reader are still unclear. This paper investigates the reader's perception of the communication of uncertainty in biomedical texts and its effects on the reader's emotions and decision making. Four versions of a scientific paper on the risks of egg consumption, with varying degrees of certainty, were submitted to participants in two pilots and two studies. The pilots reveal that although participants are sensitive to changes in degree of certainty, they are not so aware of the epistemic markers of uncertainty in the articles. Study 1 shows that with a different framing of the risks of egg consumption - increase of cholesterol vs. risk of heart attack -, (un)certainty has an effect both on participant's emotions and subsequent intentions; study 2 highlights a difference between bare "lexical" certainty (simple presence of epistemic markers) and "textual" certainty (induced by contradictory sentences).
\end{abstract}

Keywords: certainty; uncertainty; epistemic stance; effects on decision; effects on emotions

\section{Introduction}

The $21^{\text {st }}$ Century world is characterized by strict intertwinings among people, sciences, technological tools and media. This leads to a high level of complexity of the picture humans have to confront in trying to comprehend and manage the world they live in.

Like for any sort of complexity, even a tentative comprehension cannot be achieved without to some extent disentangling the intertwined aspects of the picture, and trying to understand them singularly. Nevertheless once reached a fair level of understanding of the single aspects, they must be re-combined, finally seeing the picture in its complex intertwining again. 
This is one of the points of the emerging research in CogInfoComm (Baranyi and Csapó, 2012; Baranyi et al., 2015), an interdisciplinary field that aims at "providing a systematic view of how cognitive processes can co-evolve with infocommunication devices so that the capabilities of the human brain may [...] interact with the capabilities of any artificially cognitive system" (Baranyi et al., 2015). Such field hence connects research areas such as, for instance, HumanComputer Interaction and Social Signal Processing, Affective Computing and Cognitive Linguistics, Multimodal Interaction and Brain-computer interfaces.

All these disciplines can be exploited to approach any domain in a bidirectional fashion. Not only is it necessary to have basic knowledge of one single field of human cognition and then move to its reproduction and simulation in artificial systems, but also the other way around. Simulation and the building of virtual agents endowed with the capabilities under analysis are a wonderful tool to investigate human aspects in more depth. In a word, a back and forth movement is required for an exhaustive understanding of both sides.

A topic on which the above areas can meet is a relevant aspect of human knowledge: the certainty of our beliefs.

Beliefs are representations of the world that we need when we make plans in order to reach our goals. But these representations are of use only to the extent to which we can rely on them, that is, only if we feel certain of them. Knowledge transmission is affected by this issue: namely, the receiver of our communication has the right to know how certain we are of the beliefs we convey, and we fulfill such duty by displaying the level of certainty of our communicated knowledge through verbal or multimodal markers of certainty or uncertainty.

The receiver's awareness of belief (un)certainty is of the utmost importance when it comes to information in the health domain. To help both doctors and patients assess the likeliness of facts, conditions or causal relations in biomedical literature, linguistic research must write down repertoires of verbal markers of uncertainty (Zuczkowski et al., 2016; 2017) and other attenuations of certainty (Allwood et al., 2014). In addition, multimodal analysis has to find out the typical body signals of high certainty and obviousness (Debras, 2017; Vincze \& Poggi, 2018), or uncertainty and ignorance (Bourai et al. 2017; Hübscher et al. forth.) and cognitive psychology should test sensitivity to them in human readers. It is also relying on all such investigation that computational linguistics may find tools for their automatic detection (Omero et al., forth.).

This paper, sticking to an experimental psychology approach, aims to investigate the effects of uncertain communication on interlocutors, in terms both of aroused emotions and of behaviour changes. Section 2 overviews previous works on uncertainty, while Section 3 the cognitive model of mind, action, emotion, and communication we adopt in our research. Sections 4, 5, 6 and 7 present two pilot and two experimental studies investigating the cognitive, affective and decisional 
effects of the communication of uncertainty in biomedical texts, by taking into account different types of uncertainty, linguistic and conceptual.

\section{Previous Works on Uncertainty}

Research on uncertainty runs parallel in at least two different fields: communication studies and linguistics. Both have investigated uncertainty in various domains: health, climate, work environment; but while the perspective taken by communication studies is on how to manage uncertainty and reduce the negative emotions it produces in people, linguistic studies have mainly investigated how speakers communicate their uncertainty by lexical and morphosyntactic "epistemic markers".

In the first case, research mainly focuses on the uncertainty people affected by chronic and acute illnesses live with (Babrow et al. 1998). In patients with HIV the trajectory of illness is highly variable across people, and most treatments are considered experimental, which leads to questions about their safety and efficacy (Brashers et al. 1998). In this case uncertainty is seen as something to be managed or reduced, to limit the occurrence of negative emotions (Brashers et al. 1998). Yet, although uncertainty is generally associated with anxiety (Gudikunst 1995), it encompasses a whole range of emotional even positive responses: at times it allows people affected by chronic illnesses to maintain hope and optimism (Brashers 2001). The importance of how to communicate uncertainty in scientific communication is again acknowledged by Zehr (2017). Yet Johnson \& Slovic (1995), in a study aimed to find out whether lay people notice ranges of risk estimates in simulated stories, showed that people are unfamiliar with uncertainty in risk assessment, and with uncertainty in science generally.

In the linguistic and cognitive domain. the notion of uncertainty has been dealt with from different points of view. In the sociolinguistic perspective, Jaffe (2009, 3) defines stancetaking as "taking up a position with respect to the form or the content of one's utterance". Beside the "affective" stance, related to the emotions expressed towards the ongoing object of discourse, the "epistemic" stance is defined as the speaker's attitude towards the reliability of conveyed information (Dendale and Tasmowski 2001); commitment to the truth of the message (De Brabanter and Dendale, 2008); its degree of certainty, i.e. likelihood of the proposition (Castelfranchi \& Poggi, 1998); certainty or uncertainty of the information being communicated (Zuczkowski et al., 2017).

Epistemicity is a linguistic notion, referred to the markers through which the levels of certainty and the sources of knowledge are communicated. Whether one is certain or uncertain about the communicated content is conveyed by lexical and morphosyntactic "epistemic markers": verbs like assert, adjectives like uncertain, 
adverbs like probably, verb mode like conditional or subjunctive, but also sentence types like questions, if-clauses or the epistemic future (Zuczkowski et al., 2017). The linguistic resources used by speakers/writers to mark their commitment to the conveyed information have been thoroughly investigated in linguistics (Dendale and Tasmowski 2001; Mushin 2001; Heritage, 2013; Zuczkowski et al. 2017, among others). In all this literature uncertainty is conceptualized, on the one side, as something giving rise to intense emotions (either negative, like anxiety and fear, or positive: hope), on the other, as the speaker's degree of confidence in his beliefs. In this perspective, linguists analyse how uncertainty - whatever may have caused it - is communicated to the interlocutor, in contexts ranging from everyday conversation to medical contexts (Peräkylä 1997; Maynard \& Heritage 2005; Landmark et al. 2015).

Still, we do not have a complete grasp on how the communication of speaker's/writer's uncertainty affects the Addressee (listener or reader). Only a handful of studies have taken the interlocutor into account, focusing on the effect that verbal resources have on the listener (Morency et al. 2008; Sperber et al. 2010).

\section{A Cognitivist View of Certainty and Uncertainty}

According to a model of mind, social interaction, emotion, and communication in terms of goals and beliefs (Castelfranchi \& Poggi, 1998), the life of any system is regulated by goals. The system can achieve its goals through planning of hierarchical structures of actions and goals. In order to choose goals to pursue, actions to perform, pre-conditions for actions, the system makes use of beliefs: representations of states of the world or of mental states of the system itself, acquired through perception, elaborated through inferences, stored in memory and then retrieved from it, or received through communication.

Beliefs are of vital importance for goal achievement. They are hence an essential resource for humans, and communication - i.e. providing beliefs to other people can be seen as a gift, governed by the Grician Cooperation principle (Grice, 1975): a law of "altruism of knowledge" (Castelfranchi and Poggi, 1998) that imposes humans to share true beliefs any time someone needs them. But beliefs, besides being true (a good representation of the real world) must also have a high level of certainty, as one cannot rely on uncertain beliefs for goal planning. This is why in communicating our beliefs to others we also convey how certain we are of them.

When assuming a belief in our mind, we do not only have a representation of its content, but also a meta-representation - a meta-belief stating the degree of certainty we attribute to it. The degree of certainty of a belief is determined by two factors: a first determinant is the cognitive system it comes from (perception, 
memory, inference, communication) and a meta-cognitive evaluation of its reliability. Generally, we trust our perception above all, but if I know I am a bit drunk I may not trust it so much; if I am not very self-confident I might rely more on what others tell me than on my own reasoning. The other device that raises or lowers the degree of certainty of beliefs is their processing and integration in memory. In fact, we usually compare new-coming beliefs and try to connect them through inferences with our beliefs previously stored in our long-term memory. If they are congruent, then both the new and previous beliefs are confirmed, i.e., their degree of certainty increases; if they are contradictory, either the new or the old belief are disconfirmed, and the whole belief network must undergo belief revision. Though the degree of certainty may change due to the interaction with other persons' minds, in this "cognitivist" view, certainty is not only a linguistic concept, but before being so, it is primarily a property of the speaker's beliefs. Therefore, we can distinguish between "certainty in the mind" and "certainty in communication".

Certainty can be defined as the probability an Agent subjectively attributes to the event mentioned by a belief, and since probability is a gradable property, we can say that the Agent is more or less certain of a given belief. Further, when one communicates one's beliefs to another person, s/he must not only comply with the norm of altruism of knowledge (tell the truth), but also disclose the degree of certainty of the communicated beliefs. One can do so by exploiting all the devoted linguistic devices: lexical and morpho-syntanctic epistemic markers.

This is how the level of certainty in one's mind is conveyed to another mind. But how does the Addressee process such communication, and what happens later?

\section{Perception and Effects of Uncertainty in Medical Communication. An Empirical Research}

What are the effects of certain versus uncertain beliefs on the Interlocutor's decision making? Since the main input to decision and planning are beliefs, and also their level of certainty, what is the difference in the possible decision in case the beliefs one receives are communicated as certain or not? How does the Interlocutor of an uncertain message perceive the communication of uncertainty, and how are his/her emotions and decisions affected by this possible acknowledgment?

This paper presents a research on the effects on readers of a certain versus uncertain epistemic stance taken by the author of a scientific medical text. In the context of a National Research Project on uncertain communication in the biomedical literature, focused on medical communication in a corpus of scientific 
papers published in the British Medical Journal (BMJ), we designed 2 pilot and 2 experimental studies. They were based on semistructured surveys, to investigate how certain versus uncertain messages, not directly having a persuasive intent, are processed, whether readers grasp the modulations of (un)certainty in written texts, and if different degrees of certainty impact on their emotional reactions and future behaviour.

\subsection{Hypotheses and Research Questions}

Our general hypothesis is that if someone is uncertain concerning some belief, one is less likely to take a particular course of action that the belief might induce: the degree of certainty will affect emotions, evaluations and behavioral intentions.

In particular, given an informative text conveying information that might induce a change in decision making, our research questions were:

1. are the readers aware of the degree of certainty conveyed by the text?

2. are there differences in the subsequent intended course of action, or in the strength of intention, depending on the degree of certainty explicitly or implicitly communicated?

3. are readers aware of the ways in which the degree of (un)certainty is conveyed?

4. are the emotional states possibly triggered by the text different depending on the conveyed degree of certainty?

\subsection{Materials}

To build our text stimuli, we chose a paper from the BMJ corpus on a topic of possible general interest: a study investigating the relationship between egg intake, cholesterol level, and cardiovascular risk (Rong et al., 2013). Starting from this text, we constructed a brief text in Italian concerning the relationship between the consumption of eggs and the risk of cardiovascular disease. We manipulated the level of author's certainty and fabricated three versions of texts: highly certain, certain and uncertain. Our hypothesis was that reading the uncertain version, where the causal relationship between egg intake and risk of stroke and heart attack was not expressed in a very certain way, would not induce the reader to eat less eggs per week, whereas the same content, if expressed with more certainty, might induce such a change in behavior intention.

Two pilot studies were carried out to test the messages for subsequent experimental studies. 


\subsection{Pilot 1}

The experimental design is a between-subjects study: the independent variable is the uncertain vs. certain phrasing of the text, and the dependent variable is the intention or not to eat more eggs per week than usual.

\section{Materials}

Two versions of the "eggs" text were created, one certain and one made uncertain by inserting uncertainty lexical and morpho-syntactic markers. For example, a present indicative mode in the first version was replaced by a conditional in the uncertain version, and uncertainty adverbs were added; sentences were rephrased: from 'it reduces the risk' to 'it could reduce the risk'; from 'results do not support...' to 'results do not seem to support...'.

\section{Participants and procedure}

Forty four participants (4 males, 40 females), students in Education Sciences between 19 and 63 years old, participated in the experiment on a voluntary basis. Twenty four of them were submitted the uncertain version and twenty the certain one. To begin with, participants had to answer three questions concerning their dietary habits (weekly egg consumption); dietary preferences (how much they liked eggs on a scale from 1 to 5, with 1 meaning "not at all" and 5 "a lot"); and opinions on healthy diets (whether they considered eggs a healthy food on a scale from 1 to 5, with 1 meaning "absolutely unhealthy" and 5 "very healthy"). Then they had to carefully read the text and finally fill in a second set of questions. The question on dietary habits was again presented, but now it inquired on future intake of eggs, to find out possible variation as a consequence of reading the text in one condition rather than the other. In the following six questions, participants had to assess on a scale from 1 to 5 ( 1 meaning "not at all", and 5 "a lot") whether they considered: the topic interesting, the results presented in the text surprising, the argumentation advanced in the text reliable, the results presented in the text certain; and how much they considered the relationship between egg intake and stroke and heart attack plausible. The first two items (investigating interest and surprise) were distractors, the last item (on the plausibility of the relationship between egg intake and heart diseases) was aimed to probe their prior opinion on the issue; instead, the purpose of the items 'certainty' and 'reliability' was to investigate whether participants ranked the 'certain' version higher in terms of certainty and reliability as compared to the 'uncertain' version. Each question was accompanied by an open question ('Why?'), where participants were encouraged to motivate their ranking. The last question was a manipulation check testing whether the manipulation of certainty was successful. It included six items probing the 'quality' of the argumentation advanced in the text: participants had to assess on a scale from 1 to 5 whether the argumentation advanced was (1) convincing; (2) interesting; (3) reasonable; (4) useless; (5) predictable; (6) uncertain. 


\section{Results}

The closed (yes/no) answers were subject to quantitative statistic analysis, while the open answers to a qualitative analysis. Manipulation checks are satisfactory: in the "uncertain" condition participants feel argumentations as more uncertain (2.59 vs. 2.05), more useless (2.05 vs. 1.42 ) and less trivial (1.95 vs. 2.42$)$, and their perception of uncertainty of results is significantly higher for the uncertain than for the "certain" text $(3,46$ vs 2,$9 ; \mathrm{p}<0.025)$. Further, the average number of eggs they intend to eat after reading the text is, as predicted, higher for the uncertain than for the certain text $(2.09$ vs. $1.55 ; \mathrm{p}<0.05)$. While results on the manipulation confirm that participants are sensitive to the level of certainty of a text, those on egg eating intention confirm that certainty induces change in behavior more than uncertainty: if you are informed about some risk of eating eggs, but information is uncertain, there is no reason to decrease egg intake. Yet, the results of the qualitative analysis of the open questions are quite surprising. From answers to question 11, "What, in terms of its phrasing, makes you think the text is more certain / uncertain?" participants seem to judge the text either from outside (external perspective) or from inside (internal perspective) the text.

In the External perspective participants take their personal epistemic stance towards the text, where three types can be distinguished:

1. A "scientific" critical position:

The participant does not judge the level of certainty for what appears in the text, but the scientific reliability of the results.

6. In any case, research results have to be tested across time and in relation with different samples of people

2. A personal epistemological theory

The participant has his/her own idea of what is scientific (i.e., to him/her, reliable) and what is not.

\section{1. [it is uncertain because] I do not know exactly which is the source}

3. A personal opinion

The participant simply judges the certainty of the text by comparing its content to his own opinion

\section{Every metabolism is different so I think that results only concern a probability}

An internal perspective is taken, instead, when the participant really tries to tell what aspects of the text make it look certain or uncertain, and these can be either conceptual or verbal aspects.

1. Conceptual:

The participant notes the presence or absence in the text of data, numbers, statistics, arguments, mention of the source

22. [it is certain] because the results are the consequence of statistical studies 
2. Verbal

Here participants show a true metalinguistic awareness, acknowledging that (un)certainty is conveyed by

a. Epistemic markers

12, [it is uncertain] because it is stated in the text that "the results of the analysis do not seem to show significant relations between egg consumption and risk of stroke"

b. Aspects or linguistic fragments that summarize the gist of the text.

12. "significant relations between egg consumption and risk of stroke"

c. logical coherence / incoherence of the text (argumentations)

d. stylistic elements

From a quantitative point of view, the answers mentioning verbal markers are really few. So we wondered whether the aspects that are taken to convey certainty or uncertainty in the text are different from bare epistemic markers.

\subsection{Pilot 2}

Starting from such "irrelevance" of verbal epistemic markers resulting from pilot study 1 , we designed a second pilot study: between subjects, 2 x 3 , with the independent variables text length (long / short) and level of certainty (neutral / weak uncertainty / strong uncertainty) and, as dependent variables, the same of pilot 1: egg eating intention after reading the text, perception of certainty, text evaluations.

The short version was a synthesis of the long one, and in both the level of certainty was modulated by adding several uncertainty markers or only a few, for the strong and weak uncertainty, respectively. The survey was submitted to 97 subjects, $86 \%$ females, $14 \%$ males, medium age 21,8 .

In this study the manipulation of certainty did not result effective: from an Anova analysis, the only significant result is the effect of text length $[\mathrm{F}(1,96)=3,646 ; \mathrm{p}<$ 0.05]: a longer text is perceived as more certain and more reliable. In the short text the absence of uncertainty markers makes it less certain than the long one $(2,87$ vs. 3,47 ); a medium level gives both the short and the long text the same highest degree of certainty $(3,24$ for both), while when marked as highly uncertain the short text is still slightly less certain than the long one (3,12 vs. 3,25).

The two pilot studies allowed us to tune the health message in conditions of certainty and uncertainty, given that participants' intentions resulted sensitive to the degree of certainty. But we also concluded that a longer text is in general perceived as more certain and more reliable. 


\section{Study One. Text Certainty plus Risk Level}

To gain a more articulated insight of the effects of our informative message on action intention, we designed a study varying the message seriousness.

\subsection{Hypotheses}

A relevant part of the literature on the effects of persuasive messages revolves around the framing device. As posited by Prospect theory (Kahneman \& Tversky, 1979; Tversky \& Kahneman, 1981), people are more averse to lose than they seek gains, hence the probabilities (certain vs. uncertain) of an outcome influence decisions based on their being framed as desirable or undesirable: People will be averse to risk when outcomes are presented in terms of gains, while they will seek risk when outcomes are framed in terms of loss (Grant $\&$ al., 2017). Messages concerning health may typically be framed in terms of either loss or gains (Rothman \& Salovey, 1997), and generally positive framing (gain: what goals you achieve if you do $\mathrm{X}$ ) is more effective in encouraging prevention behaviours (e.g. daily jogging or sunscreens), whereas negative framing (loss: what goals can be thwarted if you do not do X) is generally more effective in promoting behaviours aimed at early diagnoses (e.g. breast self-examination). In our Study 1, we adopted a similar approach, testing whether the same informative message had different effects depending on its being framed as more or less alarming, i.e., stating that eggs simply raise cholesterol level, or that they increase the risk of stroke or heart attack. Further, we wanted to test how a possible framing effect interacts with different degrees of certainty of the text.

\subsection{Method}

We designed a $2 \times 3$ between subject study. The independent variables were text framing (high risk, i.e. heart attack or stroke, vs. low risk, cholesterol) and text certainty (uncertain/certain/highly certain) manipulated through addition of uncertainty lexical and morphological markers: beside the dependent variables of the pilots studies - intention to eat more eggs, (un)certainty perception, text evaluation - we added a new variable of felt emotions, measured through the PANAS (Positive and Negative Affect Scale: Watson et al., 1988): participants were asked to self-assess, on a 1 to 5 Likert scale, how much had they had felt the following emotions: interested, stressed, alerted, annoyed, attentive, defective, worried, excited, embarrassed, enthusiastic, hostile, stimulated, irritable, proud, nervous, determined, agitated, strong, scared, activated, afraid. The questionnaire was submitted to 85 participants, 53 females (62\%) and 32 males (38\%), mean age 28,7 . 


\subsection{Results}

The results of this study highlight the role of manipulation on behavioural data: the Anova shows a significant interaction effect $[\mathrm{F}(1,78)=14,28 ; \mathrm{p}<0.000]$ between the variable level of risk (high vs. low) and time (before vs. after reading the text). As shown in Fig. 1, participants' opinion on how healthy eggs are is more optimistic after reading the low-risk text than the high-risk one: the intention of egg consumption increases from 3.09 to 3.32, as opposed to decreasing from 2,84 to 2,38 in the high-risk condition.

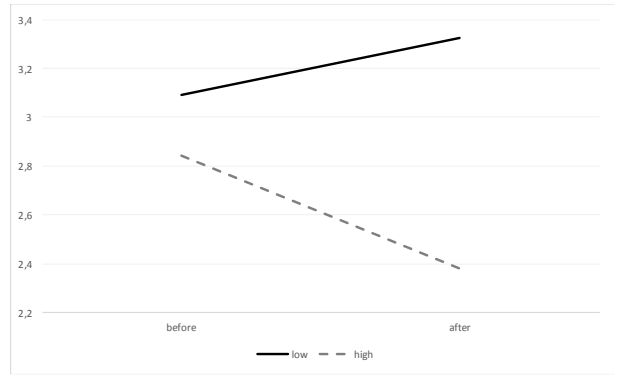

Figure 1

Healthy egg eating: Interaction effect time $\mathrm{x}$ risk

The high-low risk variable affects emotions too (Fig. 2). In the high risk condition participants feel more interest (2.96 vs. 2.32; p<0.005), stress (1.90 vs. 1.18; $\mathrm{p}<0.000)$, alert ( 2.29 vs. $1.29 ; \mathrm{p}<0.000)$ and upset (1.51 vs. 1.15$)$.

On an Anova analysis of the PANAS items, instead, the "certainty" variable only has some weak effects on the emotions annoyed $(p<0.07)$ and nervous $(p<0.06)$ : both are higher in the "highly certain" condition (Fig. 3).

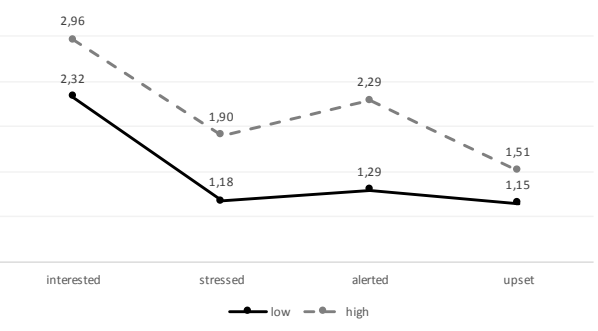

Figure 2

Main effect of risk on emotions

A significant interaction effect of the text certainty and risk is found on stress $[\mathrm{F}(1,78)=6,025 ; \mathrm{p}<0.05$; (Fig. 4) $]$ : in high-risk participants feel significantly more stress for all levels of certainty, but mainly while reading the high certainty 
text. On the contrary, the stress induced by the low-risk text has a slight decrease in the 'very certain' condition.

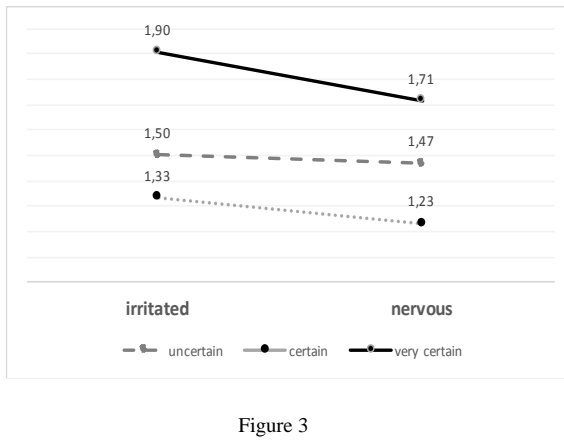

Main effect of certainty on emotions

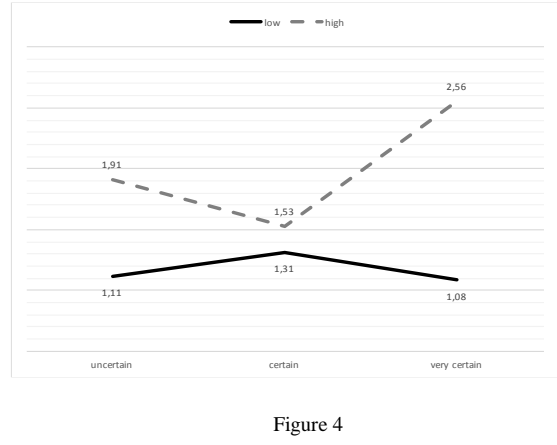

Interaction effect on stress: certainty $\mathrm{x}$ risk

The qualitative analysis on the detection of cues to certainty revealed the same categories found in pilot 1: in the external perspective, "scientific" critical position, personal epistemological theory, personal opinion, and in the internal perspective the mention of conceptual and verbal cues. But also in this study the metalinguistic awareness of participants on the text certainty results quite low. This is coherent with the quantitative result that the uncertainty of the text has a minor import, and only a high level of certainty, combined with a high level of risk, increases stress. This might be accounted for by hypothesising that the two levels of risk - high and low - activate different processes: only when the risk is high a "central" process (in terms of Petty \& Cacioppo, 1986) is activated, and consequently, the check on the level of certainty is triggered too. To better investigate this issue, and to understand why the epistemic markers of uncertainty in a text are not clearly perceived by the reader, we conducted a further study.

\section{Study Two. Risk Level Plus "Conceptual" Certainty}

What is it in a text that makes the reader feel certain or uncertain about the knowledge communicated, even independent on whether such certainty is metacommunicated by linguistic markers? As predicted by the model in Sect. 2, we become more certain of some belief as another congruent belief adds to it, whereas we start to be less certain when the new beliefs are in contradiction with the former, so as to extenuate the level of certainty it had achieved. For example, if in a text Sentence S1 states belief B1 and S2 states B2 that contrasts with B1, this undermines our trust in both B1 and B2, which both come to be assumed with a lower degree of certainty. The introduction of a new belief B2 that contradicts B1, thus lowering its credibility, may be due either to an internal contradiction of 
the writer who is himself uncertain and provides contradictory knowledge, or else to the writer quoting another source that provides contrasting information. In both cases, the reader may be puzzled by the contradiction and feel less certain on the conclusions to be drawn from that combination of beliefs.

In some sense, our hypothesis is similar to what was argued by Pastore \& Dellantonio (2016) about the existence of cues to certainty that are more in terms of text arguments; but we aimed to test it empirically on the side of the reader's perception.

The degree of certainty of the beliefs proposed by A to B may increase (confirmation) or decrease (disconfirmation). It is increased, for example,

1. when A communicates to be very certain of $X$, for instance by means of certainty markers; but also

2. when B comes to know the same belief from another source (C) considered reliable; and finally

3. when B acquires new beliefs that support belief X.

Conversely, the degree of certainty with which B assumes belief X may decrease

1. due to A's uncertainty, expressed or communicated through uncertainty markers

2. when B comes to know another belief contrasting with one communicated by A on the part of a third source (C) considered reliable

3. when B acquires other beliefs that directly or indirectly contradict the previous belief by stating of letting B infer an opposite one

\subsection{Hypothesis}

To determine the level of certainty embedded in a text, one should not confine oneself to the scrutiny of epistemic markers: the increase or decrease of certainty is not affected only by words, but by the combination of sentences and the specific beliefs they convey.

We should then distinguish two types of cues to uncertainty in a text. The first type, that we call "linguistic" certainty, is one explicitly conveyed by certainty markers, namely lexical markers like think, belief, certain, perhaps, seem, appear, and morphosyntactic markers like subjunctive, conditional, if-clause. The second type, that we call "conceptual" certainty, includes two subtypes. In some cases, that we call "textual" or "argumentative" certainty, (un)certainty is not explicitly marked at all, and can only be drawn by understanding the text sentences and their logical relationships: this is the case, for instance, when the belief communicated by a sentence is contradicted, attenuated or limited by those of subsequent sentences. A frequent case of this is the Section "Limitations" that is often present 
in scientific papers (Scardigno et al., forth), which typically downgrades the assertive attitude of the Authors by stressing possible flaws and hence, by restricting the application of results, lowers their reliability.

In other cases, that we call "phrasing" certainty, some explicit expression of high or low certainty is present, but it does not exploit the classical epistemic markers. Compare for example these two sentences: "there is a strict relationship between eggs consumption and cardiovascular disease" and "there is some relationship between eggs consumption and cardiovascular disease". The first conveys certainty in its asserting that eggs may cause cardiovascular disease, while the second is more doubtful about the same relation: the level of certainty is embedded in the words "strict relationship" and "some relationship", so it is "linguistic"; but the words some and strict do not always convey this meaning, they do so only in this context: unlike epistemic markers, they are not "codified" with a meaning of (un)certainty. To test the existence and relevance of a "textual" certainty, we moved from the hypothesis that a particular case of uncertain text is a contradictory one, and predicted that a text in which sentences point to opposite directions is more uncertain than one with all congruent sentences. Of course, this type of uncertainty might require more deep processing of the given information (Craik and Lockhart, 1972), since it occurs more at a sentence-level or text-level, unlike the processing of simple lexical or morphosyntactic markers. But this might make its perception clearer and its memory longer lasting.

\subsection{Materials and Method}

We designed a $2 \times 2$ between subject study with the independent variables textual certainty (certain/congruent vs. uncertain/contradictory) and risk level (high alarm/heart attack vs. low alarm/high cholesterol).

To build cases of textual uncertainty we worked on the congruence / contradiction of the stimuli. Namely, in new versions of the text on egg consumption we replaced congruent sentences with contradictory ones. For instance, in the "congruent" text all sentences aim at the conclusion that eggs should be avoided, while in the "contradictory" text some sentences aim at concluding that egg consumption is safe, others that it is not. Like in Table 1.

Our prediction was that the contradictory text would be seen as less certain and induce less behavior intention than the congruent one.

101 participants (balanced for gender, 53\% women, mean age 30.02), each read one of the six texts corresponding to the six conditions. The procedure was similar to Study one. First, questions on dietary habits and preferences, opinions on healthy diets; text; repeated questions on future egg intake intention; questions about the text evaluation: certain and alarming as a manipulation check, then level of interest, surprise, convincing, reliable argumentation, strength of relationship between eggs and cholesterol or heart attack, with the open question Why. 
Subsequently, participants had to fill in the brief version of the scale on tolerance of uncertainty, and the PANAS on negative and positive emotions on a five-point Likert scale.

Table 1

Manipulation of textual certainty

\begin{tabular}{|c|c|c|c|}
\hline CONTRADICTORY TEXT & & CONGRUENT TEXT & \\
\hline $\begin{array}{l}\text { Since eggs are a relevant source } \\
\text { of cholesterol in the diet - one } \\
\text { egg contains } 219 \mathrm{mg} \text {. of } \\
\text { cholesterol }- \text { it has been } \\
\text { recommended to limite egg } \\
\text { consumption. }\end{array}$ & $\begin{array}{l}\text { NO } \\
\text { (do not } \\
\text { eat } \\
\text { eggs) }\end{array}$ & $\begin{array}{l}\text { Since eggs are a relevant source } \\
\text { of cholesterol in the diet - one } \\
\text { egg contains } 219 \mathrm{mg} \text {. of } \\
\text { cholesterol - it has been } \\
\text { recommended to limite egg } \\
\text { consumption. }\end{array}$ & $\begin{array}{l}\text { NO } \\
\text { (do not } \\
\text { eat } \\
\text { eggs) }\end{array}$ \\
\hline $\begin{array}{l}\text { unless consumption of other food } \\
\text { rich in cholesterol is decreased. }\end{array}$ & $\begin{array}{l}\text { YES } \\
\text { (eat } \\
\text { eggs) }\end{array}$ & $\begin{array}{l}\text { even if consumption of other food } \\
\text { rich in cholesterol is decreased. }\end{array}$ & $\begin{array}{l}\text { NO } \\
\text { (do not } \\
\text { eat } \\
\text { eggs) }\end{array}$ \\
\hline $\begin{array}{l}\text { Yet, eggs are also a cheap and } \\
\text { low-fat food which provides } \\
\text { minerals, proteines and } \\
\text { unsaturated fatty acids, that may } \\
\text { lower cholesterol. }\end{array}$ & $\begin{array}{l}\text { YES } \\
\text { (eat } \\
\text { eggs) }\end{array}$ & $\begin{array}{l}\text { Though eggs are a cheap and } \\
\text { low-fat food which provides } \\
\text { minerals, proteins and } \\
\text { unsaturated fatty acids, these } \\
\text { cannot lower cholesterol }\end{array}$ & $\begin{array}{l}\text { NO } \\
\text { (do not } \\
\text { eat } \\
\text { eggs) }\end{array}$ \\
\hline $\begin{array}{l}\text { In addition, in peoples following } \\
\text { a diet with a low amount of } \\
\text { carbohydrates, eggs might } \\
\text { increase concentration of HDL } \\
\text { cholesterol, which seems to have } \\
\text { a protective function against } \\
\text { cardiovascular diseases. }\end{array}$ & $\begin{array}{l}\text { YES } \\
\text { (eat } \\
\text { eggs) }\end{array}$ & $\begin{array}{l}\text { And even in peoples following a } \\
\text { diet with a low amount of } \\
\text { carbohydrates, eggs do not } \\
\text { increase the concentration of } \\
\text { HDL cholesterol, which seems to } \\
\text { have a protective function against } \\
\text { cardiovascular diseases. }\end{array}$ & $\begin{array}{l}\text { NO } \\
\text { (do not } \\
\text { eat } \\
\text { eggs) }\end{array}$ \\
\hline
\end{tabular}

\subsection{Results}

In this study, the uncertainty manipulation significantly affects our dependent variables as for behavioral intention, evaluation, and emotional reaction.

First, the Anova analysis on the certainty evaluation of the text (manipulation check) shows a significant effect $[\mathrm{F}(1,101)=14,28 ; \mathrm{p}<0.000]$ : in the certain condition the texts are perceived as more certain than in the uncertain condition $(3,04$ vs 2,71). On the contrary, texts are not evaluated as more alarming according to different risk conditions.

Second, an Anova with repeated measures shows a significant interaction effect $[\mathrm{F}(1,101)=10,03 ; \mathrm{p}<0.002]$ between level of certainty and time (before and after reading the text) as to behavioral intention. Namely, participants intend to eat more eggs after reading the uncertain than the certain version of the text $(1,808$ vs. 1,551 per week), while with the certain text their intention of egg consumption decreases (1,551 vs. 1,776) (Fig. 5). A main effect of time (before and after) $[\mathrm{F}(1,101)=10,03 ; \mathrm{p}<0.002]$ is reportable also on egg likeability because after reading the text about the risk of egg eating, participants report they like eggs less 
$(3,238$ vs. 3,119$)$ (Fig. 6$)$. A slight main effect of certainty also shows $[F(1,101)=$ $3,300 ; p<0.07]$ : when certainty increases, likeability strongly decreases.

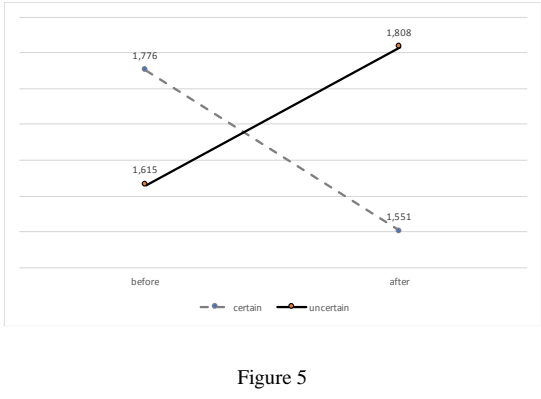

N. of eggs participants intend to eat after reading the text

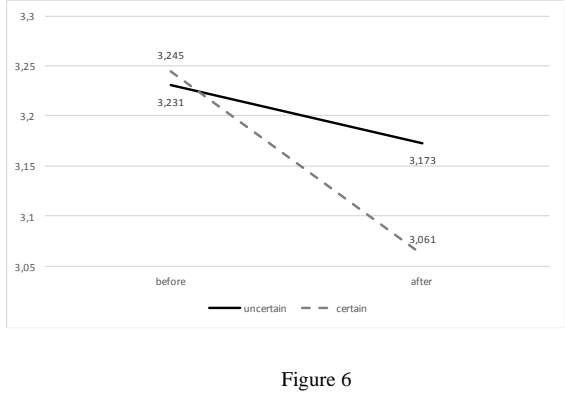

How much participants like eggs after reading the text

Eggs are judged as less healthy mainly after reading the certain text [healthy, time*certainty: $\mathrm{F}(1,101)=17,43 ; \mathrm{p}<0.000]$; but this item also shows an interaction effect: time* certainty $*$ risk $[\mathrm{F}(1,101)=8,504 ; \mathrm{p}<0.004]$ : in the highrisk condition (eggs increase heart risk), participants consider eggs less healthy, regardless of the level of uncertainty; differently in the low-risk condition (eggs increase cholesterol) if the text is uncertain participants consider eggs more healthy than after the certain text (Fig. $7 \mathrm{a}, \mathrm{b}$ ). The result on participants' belief on healthy eggs can be connected to the data of Study 1 on "linguistic certainty", where the high level of risk makes participants suspend their judgment about the degree of certainty of their beliefs. Differently, low risk enables a better assessment of the certainty of the text; this would account for why only in certain conditions does the evaluation of eggs as healthy decrease.

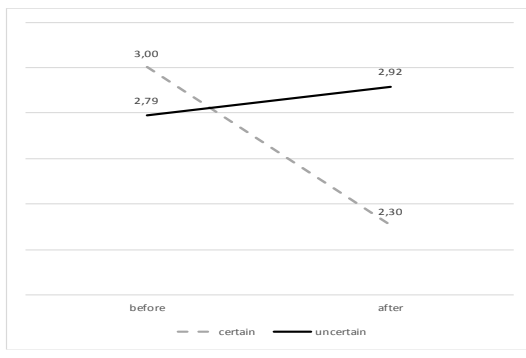

Figure $7 \mathrm{a}$

(low) How healthy do you think eggs are?

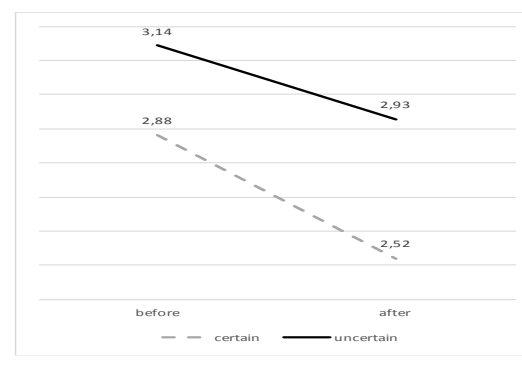

Figure $7 b$

(high) How healthy do you think eggs are?

In this study on "textual certainty", as opposed to different from the "linguistic certainty" of study 1, certainty manipulation does work: in fact, other significant effects concern the evaluation of the certain and uncertain text. Bad news make the certain text more alarming $(2,449$ vs. 1,$769 ; \mathrm{p}<0.001)$ and less reassuring ( 2.020 vs. 2,$654 ; \mathrm{p}<0.005)$, but also less inconclusive $(2,347$ vs. 2,$846 ; \mathrm{p}<0.005)$ than the uncertain one (Fig. 8). 


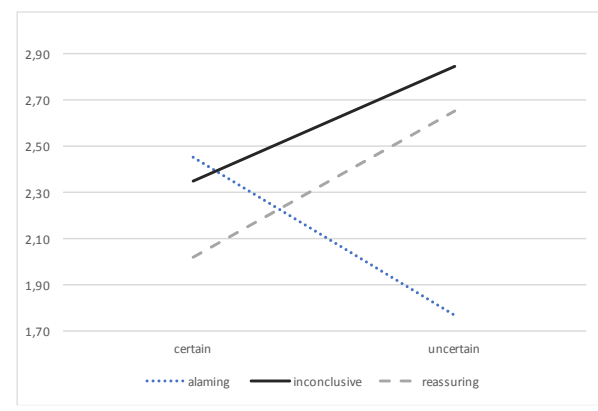

Figure 8

Text evaluations

This alarming nature of the certain text leads participants to consider also the scientific relation between eggs and heart attack more plausible compared to the uncertain text (main effect of certainty $[\mathrm{F}(1,101)=6,931 ; \mathrm{p}<0.01]$ and the issue more relevant $[\mathrm{F}(1,101)=3,801 ; \mathrm{p}<0.05]$.

A confirmation of this comes from Pearson correlations (Table 2): the alarming nature of the text is positively correlated with plausibility of the relation between eggs and heart attack, the importance of the issue and reliability and interest of the results. On the contrary, when participants judge the text inconclusive (mostly in uncertain condition) they also question the reliability and plausibility of the risky relation.

Since in this study the difference between certain and uncertain text results quite significant, the open question concerning the cues to (un)certainty is relevant. In this case, too participants" answers cluster around an "external" and an "internal" perspective, like in the previous studies.

"External perspective":

1. "Scientific" critical position:

94. [what makes it uncertain is] it's being based on statistics from a not so high nor so various a sample with regards to the possible pathologies that can affect the relationship between cholesterol and egg consumption (diabetic patients, lifestyles and feeding styles)

2. Personal epistemological theory

102. it is a scientific paper which credits it with some degree of certainty in terms of results

3. Personal opinion

39. I rarely eat eggs but my cholesterol level is high.

"Internal perspective" 
4. Conceptual:

00. It is not an argument on scientific grounds, it generically quotes studies results and draws conclusions without quoting sources, names, and contexts

5. Verbal:

Here participants show a fair level of metalinguistic awareness, acknowledging that (un)certainty is conveyed by

a. Aspects or linguistic fragments that summarize the gist of the text

38 the fact that it is argued how complex is the relation between egg consumption and risk of heart attack and stroke

b. logical coherence / incoherence of the text (argumentations)

86 I think the text presents various contradictions.

c. stylistic elements

74. The scientific style by which it is written, typical of articles in this field

Yet, no epistemic marker is quoted in their answers

An interesting aspect of participants' answers comes out when comparing this Study 2, focused on "textual" certainty, with pilot study 1, focused on "linguistic" certainty and verbal epistemic markers. In both, the "external" and the "internal" "conceptual" categories (n. 1, 2, 3 and 4) are mentioned, but within the "verbal" categories, epistemic markers are only mentioned in pilot study 1 . Instead, categories 5. a., b. and c. are almost only mentioned by participants in study 2 . This confirms that two different kinds of certainty cues can be distinguished: linguistic and textual ones.

Table 2

Correlation between Text and evaluation of results

\begin{tabular}{|c|c|c|c|c|}
\hline & & Alarming text & $\begin{array}{c}\text { Reassuring } \\
\text { text }\end{array}$ & $\begin{array}{c}\text { Inconclusive } \\
\text { text }\end{array}$ \\
\hline \multirow[t]{2}{*}{ Plausible relation } & Pearson Corr. &, $535^{\circ}$ &, $212^{*}$ &,$- 306^{*}$ \\
\hline & Sign. & 0,00 & 0,00 & 0,00 \\
\hline \multirow[t]{2}{*}{ Important issue } & Pearson Corr. &, $319^{-}$ & $=0,161$ & 0,087 \\
\hline & Sign. & 0,00 & 0,11 & 0,39 \\
\hline \multirow[t]{2}{*}{ Interesting results } & Pearson Corr. &, $358^{-}$ &, $289^{-}$ &,$- 255^{\star}$ \\
\hline & Sign. & 0,00 & 0,00 & 0,01 \\
\hline \multirow[t]{2}{*}{ Reliable results } & Pearson Corr. & $439^{-}$ & $284^{-}$ &,$- 383^{-}$ \\
\hline & Sign. & 0,00 & 0,00 & 0,00 \\
\hline
\end{tabular}




\section{Discussion and Conclusion}

The goal of this work was to investigate the ways in which readers perceive the certainty or uncertainty of a text concerning health issues, their cognitive apprehension, and their affective and motivational effects. Our hypothesis was that people could be aware not only of the degree of certainty a text conveyed, but also of the cues to it. Such prediction was not confirmed by the pilot studies, where the differences in text certainty, manipulated by adding classical epistemic markers and by varying text length, did not have relevant significant effects of certainty. If in pilot 1 . some differences were found in the effect on subsequent behavior intention, in both pilots 1 and 2 participants' awareness about what made a text more or less certain was not high.

In Studies 1 and 2, where the message framing was varied as high vs. low risk, significant results were obtained. In Study 1 the different frames elicited some significant effects both on subsequent intention and the readers' emotions. In Study 2 text certainty was manipulated not through strictly linguistic variants but through conceptual, namely argumentative devices. Such devices, combined with the differences in framing, not only had significant effects on emotions and behavioral intentions, but also showed some awareness in participants about the strategies that provide a text with a higher or lower degree of certainty.

We can draw the following conclusions: first, as predicted by previous research, the cognitive status of beliefs in a person's mind importantly affects emotions and actions; second, the degree of certainty in a text is not only - and even not primarily - manifested by strictly linguistic devices such as epistemic markers, but also, or even mainly, by higher level "conceptual" devices: for instance, by the logical relations among sentences and, possibly, rephrasing that can summarise whole sequences of text. In both our pilots and in Study 1, though participants correctly perceived the certain text as more certain, and showed future intention accordingly, their awareness of epistemic markers was low. This might mean that metalinguistic knowledge is a sophisticated capacity not so frequent in people, or else that the import of uncertainty borne by such linguistic devices is so subtle as to work almost as a subliminal cue, one that does have some effect, but is not awarely perceived. On the other hand, participants in Study 2 seem to be more at ease with that deeper comprehension of text structure that allows them to grasp text (un)certainty, and even to input it to contradictions. On the "conceptual" side of certainty cues, the congruence among sentences, investigated in Study 2, is probably only one among possible relevant devices. Other devices should then be studied, like the presence/absence of counter-arguments, or of what we have called "re-phrasing".

This research points out that the merely linguistic aspects of a text are not enough to account for the degree of certainty with which the information conveyed is finally assumed by the reader. Indeed a broader view of "certainty cues" is to be 
taken: not only epistemic markers, but several devices may be used to make a text more or less certain, and consequently have different effects on the Addressee's comprehension, emotions, and action.

\section{Acknowledgments}

The work has been in part supported by the Italian National Project PRIN n. 2012C8BJ3X, "Certainty and uncertainty in biomedical scientific communication".

\section{References}

[1] Allwood, J., Ahlsén, E., Poggi, I., Vincze, L., D’Errico, F. (2014). Vagueness, Unspecificity, and Approximation. Cognitive and lexical aspects in English, Swedish, and Italian. In S. Cantarini, W. Abraham, E. Leiss (Eds.) Certainty-uncertainty - and the attitudinal space in between . Amsterdam: John Benjamins, pp. 265-284

[2] Babrow, A. S., Kasch, C. R., \& Ford, L. A. (1998). The many meanings of uncertainty in illness: Toward a systematic accounting. Health communication, 10 (1), 1-23

[3] Baranyi, P., Csapó, A. (2012). Definition and Synergies of Cognitive Infocommunications. Acta Polytechnica Hungarica, 9 (1), 67-83

[4] Baranyi, P., Csapó, A. Sallai, G. (2015) Cognitive Infocommunications (CogInfoCom). Heidelberg: Springer

[5] Bourai, Abdelwahab, Tadas Baltrušaitis, and Louis-Philippe Morency. "Automatically predicting human knowledgeability through non-verbal cues." Proceedings of the $19^{\text {th }}$ ACM International Conference on Multimodal Interaction. ACM, 2017

[6] Brashers, D. E., Neidig, J. L., Reynolds, N. R., \& Haas, S. M. (1998). Uncertainty in illness across the HIV/AIDS trajectory. Journal of the Association of Nurses in AIDS Care, 9(1), 66-77

[7] Brashers, D. E. (2001). Communication and uncertainty management. Journal of communication, 51(3), 477-497

[8] Castelfranchi, C., Poggi, I. (1998). Bugie, finzioni, sotterfugi. Per una scienza dell'inganno. Roma: Carocci

[9] Craik, F. I., \& Lockhart, R. S. (1972). Levels of processing: A framework for memory research. Journal of verbal learning and verbal behavior, 11(6), 671-684

[10] De Brabanter, P., \& Dendale, P. (2008). Commitment: the term and the notions. In P. De Brabanter, P. Dendale (Eds.). Commitment. Amsterdam: John Benjamins, pp. 1-14

[11] Debras, Camille (2017). The shrug: forms and meanings of a compound enactment. Gesture, 16 (1), 1-34 
[12] Dendale, P., \& Tasmowski, L. (2001). Introduction: Evidentiality and related notions. Journal of Pragmatics 33(3), 339-348

[13] Grant Harrington, N., \& and Kerr, A. M. (2017). Rethinking Risk: Prospect Theory Application in Health Message Framing Research. Health Communication, 2(2), 131-141

[14] Grice, H. P. (1975). Logic and Conversation. In P.Cole, J. L.Morgan (Eds.), Syntax and Semantics. Vol. III. Speech Acts. New York: Academic Press

[15] Heritage, J. (2013). Action formation and its epistemic (and other) backgrounds. Discourse Studies, 15 (5) 551-578

[16] Hübscher, I., Vincze, L. \& Prieto, P. (forthcoming) Children's signalling of knowledge state: Prosody, face and body cues come first. Journal of Language Learning and Development

[17] Jaffe, A. (2009). Stance: Sociolinguistic Perspectives. Oxford: Oxford University Press

[18] Johnson, B. B., \& Slovic, P. (1995). Presenting uncertainty in health risk assessment: initial studies of its effects on risk perception and trust. Risk analysis, 15(4), 485-494

[19] Kahnemann, D., and Tversky, A. (1979). Prospect theory: An analysis of decision under risk. Econometrica 47, 263-291

[20] Landmark, A. M., Gulbrandsen, P., \& Svennevig, J. (2015). Whose decision? Negotiating epistemic and deontic rights in medical treatment decisions. Journal of Pragmatics, 78, 54-69

[21] Maynard, D. W., \& Heritage, J. (2005). Conversation analysis, doctorpatient interaction and medical communication. Medical education, 39(4), 428-435

[22] Morency, P., Oswald, S., de Saussure, L. (2008). Explicitness, implicitness and commitment attribution: a cognitive pragmatic perspective. Belgian Journal of Linguistics 22, 197-219

[23] Mushin, I. (2001). Evidentiality and epistemological stance: Narrative retelling (Vol. 87). Amsterdam: John Benjamins

[24] Pastore, L., Dellantonio, S. (2016). Modelling Scientific Un/Certainty. Why Argumentation Strategies Trump Linguistic Markers Use. In L.Magnani, C.Casadio (Eds.) Model-Based Reasoning in Science and Technology. Studies in Applied Philosophy, Epistemology and Rational Ethics, Vol. 27. Cham: Springer

[25] Omero, P., Valotto, M., Bellana, R., Bongelli, R., Riccioni, I., Zuczkowski, A., Tasso, C. (forth.). Uncertainty Identification in Scientific Biomedical texts: a Tool for Automatic If-clause Tagging. Computation Linguistics 
[26] Peräkylä, A. (1997). Conversation analysis: a new model of research in doctor-patient communication. Journal of the Royal society of Medicine 90.4: $205-221$

[27] Rong Y., Chen L., Zhu T., Song Y., Yu M., Shan Z., Sands A., Hu F. B., Liu L. (2013). Egg consumption and risk of coronary heart disease and stroke: dose-response meta-analysis of prospective cohort studies. BMJ; 346, 1-13. e8539. doi: 10.1136/bmj.e8539

[28] Rothman, A. J, Salovey, P. (1997). Shaping perceptions to motivate healthy behavior: the role of message framing. Psychological bulletin, 121, 1, 3-19

[29] Scardigno, R., Grattagliano, G., Manuti, A., Mininni, G. (forth.). "Certainty and uncertainty in the discursive construction of the 'dangerous lunatic'". Integrative Behavioral and Psychological Research

[30] Sperber, D., F. Clément, C. Heintz, O. Mascaro, H. Mercier, G. Origgi, D. Wilson (2010). Epistemic vigilance. Mind Language 25(4), 359-393

[31] Tversky, A., Kahnemann, D. (1981). The framing of decisions and the psychology of choice. Science 211, 453-458

[32] Vincze, L., Poggi, I. (2017). I am really certain of this! Towards a multimodal repertoire of signals communicating a high degree of certainty. In P. Paggio, C. Navarretta (Eds.) Proceedings of the $4^{\text {th }}$ European and $7^{\text {th }}$ Nordic Symposium on Multimodal Communication (MMSYM 2016), Copenhagen, 29-30 September 2016

[33] Vincze L. and Poggi I. (forth.): Multimodal Signals of High Commitment in Expert-to-Expert Contexts. Discourse \& Communication

[34] Watson, D., Clark, L. A., and Tellegen, A. (1988). A development and validation of brief measures of positive and negative affact: the PANAS scales. Journal of Personality and Social Psychology. 54 (6), 1063-1070, doi:10.1037/0022-3514.54.6.1063

[35] Zehr, S. (2017). Scientific Uncertainty in Health and Risk Messaging. Oxford Research Encyclopedia of Communication

[36] Zuczkowski, A., Bongelli, R., Riccioni, I., Valotto, M., Burro, R. (2016). "Writers' Uncertainty in a Corpus of Scientific Biomedical Articles with a Diachronic Perspectives". In Jesùs Romero-Trillo (Ed.), Yearbook of Corpus Linguistics and Pragmatics 2016. Global Implications for Society and Education in the Networked Age. Heidelber: Springer, pp. 203-241

[37] Zuczkowski, A., Bongelli, R., Riccioni, I. (2017). Epistemic Stance in Dialogue. Knowing, Unknowing, Believing. Amsterdam: John Benjamins 